\title{
TEXTO E IMAGEN EN ESPAÑA DE SOL A SOL DE ALFONSO ARMADA
}

\author{
GeneviÈve CHAMPEAU \\ Université Michel de Montaigne-Bordeaux 3
}

\begin{abstract}
RESUMEN
España de sol a sol (2001) de Alfonso Armada proporciona una muestra de la evolución del género del «libro de viajes» en la España contemporánea. Ante la imposibilidad del viaje (Marc Augé), propone renovar la percepción de lo familiar recorriendo el espacio nacional y sustituyendo el «endotismo» (Georges Pérec) al exotismo. La poética del viaje que propone el relato difiere profundamente de la de los escritores viajeros del «realismo social», en la España de los años sesenta, anteponiendo la interpretación a la información, la imagen poética a la función referencial del lenguaje, cultivando la polisemia, una intertextualidad masiva y una reflexión metatextual. Distintos son también los vínculos que se establecen entre texto e imagen, de complementariedad más que de redundancia. La fotografía participa activamente, por la reelaboración de tópicos, del dispositivo argumentativo destinado a favorecer la adhesión del lector-espectador al mensaje y se afirma, por otra parte, como experiencia estética autónoma.
\end{abstract}

Palabras clave: Relato de viaje, España, siglo XXI, Alfonso Armada, Texto e imagen, «endotismo», metatextualidad.

\section{TEXT AND IMAGE IN ESPAÑA DE SOL A SOL BY ALFONSO ARMADA}

\begin{abstract}
España de sol a sol (2001) by Alfonso Armada gives an example of the development of the «travel narrative» genre in Spain today. Faced with the «end of travel» (Marc Augé), he proposes a renovation of the perception of the familiar by travelling across Spain and Portugal and by substituting «endotic» (Georges Pérec) for exotic.The poetics in the narrative differs greatly from that by travelling writers of «social realism», in the Spain of the sixties. Interpretation replaces information, the poetic image prevails over the referential function of language, and polysemy, omnipresent intertexuality and metatextuality play an important part. The change also affects the links between text and image, which are now more complementary than redundant. Playing with stereotypes, the photography actively contributes to establishing argumentative strategies meant to make the reader-viewer adhere to the message, all while affirming itself as an autonomous aesthetic experience.
\end{abstract}

Key Words: Travel narrative, Spain, XXI century, Alfonso Armada, text and image, «endotic», metatextuality. 
El etnólogo Marc Augé titula uno de sus libros L'Impossible voyage, «el que ya no haremos nunca más, el que hubiera podido hacernos descubrir paisajes nuevos y otros hombres, que hubiera podido abrir para nosotros un espacio de encuentros» ${ }^{1}$. Ya no existen territorios y civilizaciones ignorados, la industria del ocio acorta distancias, democratiza el viaje, uniformiza los servicios, propone remedos de exotismo en parques de atracciones mientras que publicidad y reportajes homologan estereotipos. «¿De qué placer podríamos gozar hoy día ante el espectáculo estereotipado de un mundo globalizado?» pregunta el etnólogo 2 .

Las aventuras y conquistas actuales son principalmente de tipo económico o deportivo. Los medios de comunicación celebran las hazañas de los competidores como en la carrera de veleros del «Vendée Globe» calificada en la web de los organizadores de «Everest de los mares» ${ }^{3}$. Lo nuevo puede cifrarse en el medio de locomoción como en la travesía del polo norte en trineo por Jean-Louis Étienne (1986) calificada de «aventura audaz, digna de las novelas de Jules Vernes ${ }^{4}$ o en la vuelta al mundo en bicicleta de Alexandre Poussin y Sylvain Tesson ${ }^{5}$. La novedad se cifra aún en la extensión del viaje — tres años y tres meses, de África del Sur a Israel-, para Alejandro Poussin y su esposa Sonia que concretaron entre 2001 y 2004 su proyecto de seguir los pasos de los primeros hombres ${ }^{6}$. Estas formas actuales del viaje, que siguen solicitando los arquetipos del imaginario colectivo (hazaña individual, magnitud de la empresa, obstáculos que superar, azar, peligro, heroísmo) merecerían un estudio aparte.

Ante el imposible viaje de descubrimiento, siempre queda la posibilidad del redescubrir y revitalizar lo cercano, desplazando la novedad de los territorios recorridos a la misma mirada del viajero mediante «una observación liberada del sueño de la costumbre» ${ }^{7}$. Es lo que hacen los viajeros que siguen recorriendo hoy día la Península Ibérica prolongando una tradición literaria que se remonta al siglo XIX. Alfonso Armada, autor de España de

${ }^{1}$ AUGÉ, Marc. L’Impossible Voyage. Paris: Éditions Rivages Poche, 1997, p. 13. Colección Petite Bibliothèque; la traducción es mía.

${ }^{2}$ Ibidem, p. 14.

${ }^{3}$ «Vendée Globe 2012. J - 2 ans». URL. http://www.vendeeglobe.org, consultado el 20 de noviembre de 2010.

${ }^{4}$ «Jean-Louis Étienne prépare sa nouvelle traversée du Pôle Nord en ballon Rozière». En: www.radio.org, página consultada el 20 de noviembre de 2010.

${ }^{5}$ Publican su expedición en On a roulé sur la terre, título que parodia uno de los volúmenes de las aventuras de Tintín, On a marché sur la lune.

${ }^{6}$ Este viaje se contó en los dos tomos de Africa Trek, 14000 kilomètres dans les pas de l'Homme. París: Pocket, 2007. Se han vuelto unos best sellers y dieron lugar a una serie televisiva que gozó de un éxito internacional.

7 «Une observation décapée du sommeil de l'habitude». (MÉAUX, Danièle. Voyages de photographes. Saint-Étienne: Publication de l'Université de Saint-Étienne, 2009, p. 213. 
sol a sol $(2001)^{8}$ es uno de ellos. Su libro ofrece una muestra de la evolución de la poética del género en la última literatura española, en el contexto de una sociedad posindustrial y de un mundo globalizado. Además de ser autor de dos libros de viajes, es reportero de $A B C$ en Nueva York, dramaturgo y poeta, lo que le lleva a plantear la cuestión de las relaciones entre el relato de viaje, la prensa y la literatura, tipos de discursos con los que dialoga el primero. España de sol a sol presenta además la peculiaridad de asociar a partes iguales texto e imagen, puesto que cada una de las cincuenta y una secuencias viene acompañada de una fotografía — varias en algunos casos- de Corina Arranz, su compañera en el viaje y en la vida. España de sol a sol permite por consiguiente analizar una hibridez semiótica que corre paralela a la hibridez pragmática constitutiva del género del relato de viaje ${ }^{9}$, tanto más interesante cuanto que el régimen pragmático de la imagen es tan ambiguo como el del relato de viaje por su estatuto de indicio (huella del objeto que estuvo en un instante determinado delante del objetivo) y de icono (interpretación por el espectador de una «casi percepción» por analogía con lo que ya conoce $\left.{ }^{10}\right)$. Como el relato de viaje, la imagen es a la vez documento y monumento ${ }^{11}$ y nos invita a preguntarnos qué interacciones operan entre los dos sistemas semióti$\cos$ y qué funciones desempeña hoy día la imagen en este género.

Empezará la reflexión por el examen del relato porque, como lo subraya J. M. Schaeffer, las funciones de la imagen y las significaciones que se le atribuyen vienen determinadas en gran parte por su entorno verbal que convierte la mera huella física en signo capaz de transmitir una aserción sobre el mundo ${ }^{12}$. Esta subordinación, patente en su función informativa, no impide que pueda conquistar su autonomía, como lo observaremos, en la vertiente reflexiva y artística del libro, movilizando medios expresivos propios.

${ }^{8}$ ARMADA, Alfonso. España de sol a sol. Cuaderno de estío. Viaje de cincuenta y un días por la Península Ibérica en verano 2000. Barcelona: Ediciones Península, 2001.

9 Véase ALBURQUERQUE GARCÍA, Luis. «Periodismo y literatura: el 'Relato de viajes' como género híbrido a la luz de la pragmática». En: HERNÁNDEZ DE GUERRERO, José Antonio; María del Carmen GARCÎA TEJERA; Isabel MORALES SÁNCHEZ y Fátima COCA RAMÍREZ (eds.). Retórica, Literatura y Periodismo. Actas del V Seminario Emilio Castelar. 2004. Cádiz: Publicaciones de la Universidad de Cádiz, 2006, noviembre-diciembre, pp. 187-176, más particularmente pp. 171 y 172. La presencia de relato e imagen justifica el que se recurra en este artículo a la denominación «libro de viaje» para designar el conjunto icónico-verbal, reservando la denominación «relato de viaje» para las secuencias verbales.

${ }^{10}$ Véase SCHAEFFER, Jean-Marie. L'image précaire. Du dispositif photographique. Paris: Seuil, p. 101. Colección Poétique.

${ }^{11}$ Ibidem, p. 158.

${ }^{12}$ Ibidem, pp. 145-146. 


\section{El RELATO DE VIAJE COMO RESISTENCIA}

El relato de Alfonso Armada se presenta de entrada como fruto de una experiencia itinerante, de un bagaje cultural y de una postura ética que determinan su configuración. En estas condiciones, la función informativa del relato se relega al segundo plano a favor de la función interpretativa, más precisamente de una intencionalidad polémica, en un dialogismo orientado hacia la refutación de otras posturas vitales y otros tipos de discursos contemporáneos. El contexto discursivo es otro referente insoslayable de la narración del viaje.

\subsection{Un relato polémico}

\section{Viaje vs turismo}

El título España de sol a sol se refiere al marco temporal del viaje, los meses más calurosos del verano, entre el 15 de julio y el 3 de septiembre de $2000^{13}$, dando lugar cada etapa a un artículo en $A B C$ antes de que se reuniera el conjunto en un libro. El título es polisémico ya que alude también metonímicamente a las vacaciones veraniegas, el «dolce far niente» (p. 19) al que se entregan hombres y mujeres de vidas escindidas «entre ocio y trabajo, entre asueto y condena» (p. 72). El viaje coincide, por consiguiente, con las migraciones turísticas en contraste con las cuales se define. Desde el título «Fuga de la muerte» de la secuencia inicial, que desempeña funciones de prólogo, se interpreta en efecto la trashumancia veraniega como un desplazarse no tanto «en busca de» (lo que se espera de un viaje) como «para huir de», y el verano como «una estación de fugas» (p. 21):

Lo que importa no es el viaje en sí, sino llegar cuanto antes para disfrutar del tiempo libre en lugares que se van homologando como sucursales de una cultura global que borra diferencias y anula la posibilidad de conocer y conocerse. Playas, sol, paellas, helados, sonidos, encuentros, olvidos... (p. 60).

El viaje se vuelve resistencia al olvido, a la negación de la realidad, a los efectos deletéreos de una cultura que el filósofo de la postmodernidad Gilles Lipovetsky calificó de «era del vacío» ${ }^{14}$. Por su carácter polémico, este relato no deja de recordar, en otro contexto político, según otras modalidades y con otros objetivos, los relatos de viajes del «realismo social» de los años sesenta con el que comparte el mismo dualismo ${ }^{15}$.

\footnotetext{
${ }^{13}$ Cf. «Referencias». En: España de sol a sol, op. cit., pp. 285-287.

${ }^{14}$ LIPOVETSKY, Gilles. L'ère du vide. Paris: Gallimard, 1983.

${ }^{15}$ Véase CHAMPEAU, Geneviève. Enjeux du réalisme dans le roman sous le franquisme. Madrid: Casa de Velázquez, 1995.
} 


\section{Relato de viaje $v s$ periodismo}

Aunque obra de periodista, publicada primero en el diario ABC, España de sol a sol dista mucho de ser un reportaje. Las entregas presentan la misma ambivalencia, entre reflexión sobre la actualidad y relato literario que las columnas firmadas por escritores. Más que la información que pueda proporcionar, lo vincula con la prensa la relación conflictiva que con ella establece el narrador: los periódicos fallan en el cumplimiento de su función informativa e «intentan fabricar balsas que mitiguen al mismo tiempo el calor y el hastío» (p. 19). Incluso fuera del período veraniego, se reprocha a los medios informativos su escasa ayuda en la comprensión de la realidad: «tan pocas veces acontece que el periódico descifre nuestra época [...] venden la falacia de estar contando la historia en marcha y en directo» (p. 277). A. Armada denuncia, como lo hacía medio siglo antes el «realismo social», una perversión de la función referencial del lenguaje a propósito de «las palabras que han dejado de decir lo que decían» (p. 230). Mientras que los viajeros de los años sesenta del pasado siglo la emprendían con la propaganda política del franquismo, España de sol a sol arremete contra una opacidad más difusa y global, irreductible según los teóricos de la posmodernidad porque ya no existe centro organizador, sistema centrípeto ni explicación global que valga ${ }^{16}$. Alfonso Armada rechaza este relativismo por generar impotencia y $\operatorname{pasividad}^{17}$ y sigue anhelando un modelo epistemológico explicativo de la realidad, del que participe la literatura. En el título polisémico España de sol a sol, la luz solar metaforiza la que puede echar el relato sobre una realidad compleja que es preciso interpretar (el narrador recuerda con Paul Celan que es preciso «no dejar de dialogar con las fuerzas oscuras», p. 20). Este anhelo de desciframiento se transparenta en la percepción del paisaje como letras (p. 136), jeroglífico (p. 277), dibujo oculto (p. 278), ofrecidos a la investigación del viajero y del lector.

\section{Endotismo vs exotismo}

«Tal vez una de nuestras tareas más urgentes — escribe Marc Augésea reaprender a viajar, eventualmente a lo más cercano a nosotros, para

${ }^{16}$ Cf. LYOTARD, Jean-François. La condition postmoderne. Paris: Éditions de Minuit, 1979 y VATTIMO, Gianni, et al. En torno a la postmodernidad. Barcelona: Anthropos, 1990.

${ }_{17}$ «[...] las audiencias, los públicos, los seres se vuelcan ante el espectáculo de la propia consumación y los periodistas hemos perdido las agallas, norte, sur, puntos cardinales, sangre con la que hacer morder el polvo a la derrota» (p. 230). 
reaprender a mirar» ${ }^{18}$. Nada mejor que lo familiar $-\mathrm{o}$ supuestamente talpara entender lo que dista entre «mirar» (con los ojos) y «ver» (o sea entender) y cómo pueden volverse antitéticos los términos «circular» y «ver»: «Cada vez se circula más. Cuanto más se circula, menos de ve» (p. 253). Al exotismo opone A. Armada, aunque sin emplear la palabra, el «endotismo», término aplicado a la literatura por Georges Pérec ${ }^{19}$ que designa con él una percepción renovada de los mundos próximos y familiares a los que no se suele prestar atención, de todo aquello que, sin constituir un acontecimiento digno de figurar en los diarios, nutre sin embargo nuestra vida diaria:

Lo que pasa de veras, lo que vivimos, el resto, todo el resto, ¿dónde está? Lo que ocurre cada día, cada día se repite, lo banal, lo cotidiano, lo evidente, lo común, lo ordinario, el ruido de fondo, lo habitual, cómo dar cuenta de él ¿cómo interrogarlo?, ¿cómo describirlo? [...] Cómo hablar de esas cosas comunes, o más bien como volverlas visibles, cómo liberarlas de esa ganga de la que quedan presas, como darles un sentido, una lengua para que hablen por fin de lo que es, de lo que $\operatorname{somos}^{20}$.

Reeducar la mirada exige que se modifique el ethos del viajero narrador, o sea la imagen que da de sí mismo en el relato, lo que se consigue en España de sol a sol gracias a una postura triplemente excentrada: la del español que, residiendo en Nueva York, mantiene una relación distanciada con su tierra («quisiera ser capaz de escuchar como un extranjero en mi propio país», «mirar con la perplejidad curiosa del recién llegado», p. 20), la de un gallego que adopta la identidad imaginaria de un portugués (p. 254) y la de un adulto que intenta recobrar la capacidad de asombro de un niño («poner [...] ojos de niño», pp. 238-239).

\subsection{Poética de lo infraordinario}

\section{Selección y fragmentación}

Devolver visibilidad y sentido a lo común supone primero una selección drástica de lo contado. El viajero-narrador de España de sol a sol excluye lo llamativo - lugares y monumentos turísticos, paisajes famosos, espacios cargados de historia, ciudades grandes- en beneficio de lugares menos conocidos, por eso localizados en un mapa al principio de las secuencias, espacios al margen del turismo, «intrahistóricos», según el término acuñado por Unamuno, como pueden serlo un bar de carretera, quintaesencia de la vida provinciana, o «no-lugares» tales como un motel, un quiosco,

\footnotetext{
${ }^{18}$ AUGÉ, Marc. L’Impossible Voyage, op.cit., p. 15; la traducción es mía.

${ }^{19}$ PÉREC, Georges. L'infra-ordinaire. Paris: Seuil, 1969, p. 12.

${ }^{20}$ PÉREC, Georges. «Approches de quoi?». En: L'infra-ordinaire, op. cit., pp. 9-13; la traducción es mía.
} 
una gasolinera, un «puticlub» o descampados suburbiales. Es emblemática por su intrascendencia la descripción de Oropesa:

[...] un cenador sin grandes promontorios, sin turbadoras bellezas, sin accidentes geográficos que quiten el aliento ni vetas históricas cargadas de tanto significado que no dejen conciliar el sueño. Acaso sea el secreto de esta Oropesa del Mar donde el azul es tan nítido que no hay discusión posible, sólo sentarse a escuchar la quejumbre de las olas, leve, intrascendente, como una conversación de esponjas (pp. 148-149).

Para celebrar lo cotidiano, el relato introduce espacios insólitos en un relato de viaje, lo reprimido de la sociedad, los espacios del dolor: cuenta una visita a una unidad de cuidados intensivos (pp. 99-103), a una cárcel de mujeres (pp. 241-247), a los invernaderos de El Ejido, símbolos de exclusión social y racismo (p. 187), a las tumbas anónimas de los candidatos a la inmigración, en un cementerio de Algeciras (pp. 221-231), a los nightclubs de Marbella (pp. 209-215).

Aunque la estructura del relato respeta el orden del viaje, su organización semántica depende de criterios ideológicos, de una visión nostálgica y desencantada del presente. El viajero narrador recurre a la experiencia itinerante para demostrar, gracias a la diversidad de situaciones y a la recurrencia de los motivos, una tesis previa expuesta metafóricamente desde la primera secuencia que proporciona una interpretación global de la realidad en el título ya mencionado «Fuga de la muerte» que introduce tres planos de interpretación. Las vacaciones simbolizan una sociedad que huye de una realidad insatisfactoria, de unas «ciudades-monstruo» (p. 273) y de un «tiempo deshabitado (p. 266)», en vez de intentar cambiarlos: «ahora, nadie se mueve por nada» (p. 274). Los muertos en accidentes de tráfico añaden una vertiente existencial a la precedente. El término «fuga» es aún metanarrativo puesto que designa el principio musical de variación a partir de la metáfora inicial que determina la articulación de las unidades del relato.

Para revitalizar lo cotidiano, España de sol a sol prefiere la intensidad a la extensión, tanto en el área espacial como temporal. Un relato fragmentario entrega la percepción subjetiva del viajero en un instante determinado. Son escasas las referencias al trayecto y a las condiciones materiales del viaje. Las descripciones escuetas — son relativamente prescindibles cuando se recorre un espacio familiar - se ordenan en una yuxtaposición de impresiones fugaces, en un relato dominado por la parataxis. De Madrid se describe un fragmento diminuto de paisaje, que podría ser de cualquier otro lugar, contemplado en dos momentos distintos, tal vez tras el cristal de una ventana:

Toda la belleza del mundo cristaliza a las siete en punto de la tarde contra una pared tan blanca como la cal de Zurbarán y la sombra de un olivo que salva la 
tapia y se queda temblando a merced de la brisa que se ha desplomado como si Madrid hubiera muerto. Cuando la noche embadurna el azul cobalto del cielo, la luna que rueda sobre la tapia parece un gato lamiendo. Luna llena, hostia de los incrédulos (p. 24).

En Mondoñedo, se encadenan la evocación de una colada que flota al viento, de un gato dormido, de un pie que se mueve rítmicamente y de un perro que alza la cabeza hacia el cielo, (p. 83). El recorte y la yuxtaposición de visiones parciales generan una poética del detalle que produce un efecto de lente de aumento. Se confirma lo que subrayó Patricia Almárcegui a propósito de la última literatura de viajes, que la intensidad de la experiencia importe más que la cronología ${ }^{21}$.

\section{Entre testimonio e interpretación}

El endotismo practicado por A. Armada ambiciona remontarse, por inducción, de la experiencia viajera de lo cotidiano y familiar a una interpretación de la realidad del hombre en la cultura global posindustrial. El yo del narrador, alrededor del cual la literatura contemporánea organiza y legitima el proceso hermenéutico, se funda para ello en su triple estatuto de viajero, periodista y poeta, identidades que se refuerzan en vez de excluirse.

Ocupa el primer plano el periodista en las secuencias dedicadas a temas de actualidad (narcotráfico, inmigración clandestina, prostitución, hospitales y cárceles o desertificación del campo) y delega masivamente la función testimonial a las personas / los personajes entrevistados. En otros casos, su voz emerge de modo más puntual, integrada a la narración (véanse por ejemplo las páginas 118 y 164). Que los enunciados citados sean de mucha extensión y tipográficamente destacados o integrados en el discurso narrativo, excluyen prácticamente la forma clásica del diálogo que producía un efecto de realidad. En España de sol a sol, permanece siempre tangible la mediación de la instancia narradora, en particular en la teatralización de la voz de los testigos. La secuencia 10, dedicada al narcotráfico (pp. 6369), y la 17, dedicada a una unidad de cuidados intensivos (pp. 99-103), recurren a una ficción teatral: división en seis escenas que corresponden a las seis entrevistas en el primer caso, mención del escenario y de los actores en unas como didascalias en el segundo. La interferencia entre los registros periodístico y teatral evidencia la reelaboración literaria de la documentación poniendo de relieve la función fática del lenguaje, centrada en el contacto (en este caso el mensaje verbal se reviste de la visualidad del teatro o de la televisión) y de la función conativa centrada en el destinatario, puesto que la mimesis de medios de expresión visuales dramatiza la representación, solicitando la afectividad del receptor.

${ }^{21}$ Véase ALMARCEGUI, Patricia. «Cómo escribir hoy un libro de viaje». Quimera, oct. $2009, \mathrm{n}^{\circ} 311$, p. 38. 
La vertiente existencial del viaje cristaliza en biografemas que lo insertan en una temporalidad individual, real o imaginaria. La secuencia 13, «El bosque de la noche», se dedica al parque de un pazo gallego cuyos propietarios llevan desde hace siglos el apellido Armada, el del mismo viajero, y le sugieren a éste un viaje imaginario a los orígenes míticos del mundo, mientras que la secuencia 22, «El secreto de Numancia», dedicada al equipo de fútbol de Berlanga de Duero que encarna, como lo veremos más adelante, la ética de la resistencia que defiende el narrador, se refiere a una comarca en la que el autor residió durante su juventud. Los biografemas son escasos pero suficientes para articular lo individual y lo colectivo, lo existencial y lo societal, una característica del libro que lo diferencia de sus predecesores de los años sesenta del pasado siglo y en la que se manifiesta el paradigma hermenéutico de un tiempo que no disocia el saber de la vivencia.

La interpretación subjetiva que configuran abundantes comparaciones y metáforas confiere un tono poético y lírico al relato. Los paisajes son antes que todo «paisajes del alma» recreados por imágenes en parte insólitas, equivalente retórico del exotismo (un aguacero se asimila a un tren de mercancías, un aserradero a un zigurat, p. 75; una playa a un serón de acunar niños, p. 71; un burro a un unicornio, p. 79). La imagen ocupa el centro de un dispositivo poético con pretensiones hermenéuticas. El tratamiento metonímico-simbólico del espacio y de los personajes mantiene una tensión permanente entre lo particular y lo general, lo concreto y lo abstracto, rasgo que este relato de viaje comparte con la novela de tesis ${ }^{22}$. El relato declina la metáfora inicial del viaje-fuga en variantes que atañen la existencia individual (accidentes, drogadicción), que afectan un grupo humano (inmigración, racismo) o la mayoría de los ciudadanos (la realidad urbana de las megalópolis y sus afueras que no son «ni carne ni pescado» - p. 265-, como la ciudad dormitorio de Getafe — pp. 269-275- o Brunete — pp. 265267). En función de esta metáfora central, con fuerte significado ideológico, se reparten los personajes en clases semánticas bien diferenciadas: los adeptos del dinero fácil (narcotraficantes, proxenetas y prostitutas, propietarios de invernaderos), los que no pueden huir o fracasan en la huida, víctimas del sistema económico-social o de la vida (marginados, candidatos a la inmigración que perecen en el Estrecho, víctimas del racismo, pero también enfermos). Una tercera clase reúne a los heraldos de la ética de la resistencia: el campesino que no contribuye a la desertificación del campo, el peón caminero al pie del cañón cuando sus conciudadanos se van de veraneo, los miembros del club de futbol «El Numancia» que rechazan la comercialización del deporte y el star-system. A ellos se suma el torero

${ }^{22}$ Véase RUBIN SULEIMAN, Susan. Le roman à thèse ou l'autorité fictive. Paris: PUF, 1983. Coll. Écritures. 
José Pacheco que se juega la vida para forjarse una personalidad que lo aleje del anonimato de los que alimentan la noria urbana: «Lo que yo quiero es sacar todo lo que llevo dentro. Tener personalidad es lo más importante» (p.198). El relato confronta pues ser y deber ser conformemente a la dualidad de los discursos polémicos ya apuntada. El deber es aún patente en la figuración emblemática del espacio como se observará en la contraposición de dos tratamientos del paisaje primero como disyunción disfórica del hombre y de su entorno (el ser) y luego como conjunción armoniosa y eufórica (el deber ser). El primero, síntesis de percepciones diversas, se sitúa en la secuencia 9 titulada «La montaña herida»:

La autovía de las Rías Bajas es la obra de ingeniería civil de un cíclope que no ha tenido contemplaciones a la hora de raspar la piel de las montañas, de abrir la roca viva [...]. Cuando estamos a bordo del vehículo que nos lleva sólo ansiamos que el tiempo pase pronto, que la geografía se encoja y no dure. Vemos el color cambiante de los estratos, pero desde un pasillo aislante, una cápsula de tiempo. Se trata de un cordón sanitario con la realidad de los pueblos que se quedan más allá de la barrera protectora, arcenes, quitamiedos y verjas que cortan la tierra en dos (p. 60).

La segunda descripción convierte un rincón andaluz próximo a Vejer de la Frontera en un espacio igualmente ideologizado, en el que apunta la nostalgia de una civilización rural en vías de desaparición convertida por el léxico en una visión paradisíaca:

Tras las empalizadas, las garzas parecen haber hecho amistad con el ganado. Nadie molesta a nadie. La tarde se va entre pláticas, ese «callarse juntos» que Benjamín Carrión gastaba con Juan Rulfo. Así se callan los campos de Cádiz, suaves colinas y prados domesticados que van a dar al mar, dehesas y encinas de sombra que son el paraíso de los toros. Levanta el vuelo una bandada de garzas y vuelve a posarse junto a las vacas inmutables. Hace lo mismo una bandada de cuervos y los toros siguen engastándose los cuernos en un toma y daca de juego. La carretera no parece aquí una herida. Se despliega mansa entre pastizales, mientras el ganado sigue a lo suyo, rumiando el tiempo bajo un sol que el atardecer vuelve dulce como si no tuviéramos culpa de nada (p. 234).

\subsection{Intertextualidad y reflexividad}

Si escasean las informaciones prácticas sobre el viaje, menudean en cambio las referencias culturales que aclaran la intencionalidad del libro, contribuyen a la reflexión metadiscursiva sobre el género, bosquejan una ética del viaje y constituyen una modalidad privilegiada de continuidad espacio-temporal de tipo cultural al reunir escritores de varios países y épocas. La intertextualidad es masiva y declarada. Los principales maestros del viajero se mencionan desde el principio: Paul Celan asociado a la metáfora de la muerte, Hans Magnus Ensensberger y su libro Cristales rotos de Es- 
paña, Henry Roth maestro en describir lo infraordinario y Cervantes que sabe de «descifrar la piel de los hombres» (p. 20). Cada porción del territorio es un palimpsesto de relatos previos (referencias y/o citas), como los de Cunqueiro en Galicia, de Pla en Cataluña y por supuesto de Cervantes en la Mancha. El filtro literario está presente en los títulos que mencionan el nombre de un autor ( Gil de Biedma entre pinares», «La linterna de Machado», «Josep Pla, paisajista y fingidor»), de un personaje («La sombra de Don Quijote») o que reproducen o parodian otro título («El mismo mar de todos los veranos», título de una novela de Esther Tusquets, «Esperando a Godot en Brunete», deformación de Esperando a Godot de Samuel Beckett, «El árbol fieramente humano» que recuerda El ángel fieramente humano de Blas de Otero). Un episodio del viaje, un enunciado descriptivo, pueden ser comentados por una cita o una referencia cultural. El relato de viaje queda, de este modo, claramente insertado en el área literaria. Añadamos que los interlocutores del viajero son a menudo escritores, periodistas, dramaturgos - también el escultor Leiro- cuya postura vital y creadora contrasta con la ceguera y el escapismo de los adeptos del asueto veraniego. José Jimenez Lozano, escritor y erudito, «buen castellano viejo» (p. 53), que ha escogido la vida retirada en un pueblo cercano a Olmedo, probablemente sea el mejor representante del ideal humanista que propone España de sol a sol. Tampoco pueden olvidarse las tres secuencias, entre las primeras, dedicadas a Almagro, su festival de teatro y a algunas figuras de dramaturgos. La literatura no es adorno del relato sino medio de interpretación de la realidad y respuesta ética que aúna lucidez, convivencia y diálogo. Se aplica a España de sol a sol el comentario del narrador acerca de Baía dos Tigres, relato de un viaje entre Angola y Mozambique del escritor portugués Pedro Rosa Mendes: «tal vez sea la novela la única forma de residir y de resistir» (p. 253).

\section{LA FOTOGRAFÍA ENTRE DOCUMENTO Y MONUMENTO}

Fruto de la colaboración de un escritor y una fotógrafa que viajaron juntos, España de sol a sol atribuye la misma importancia a las fotos y al texto que alternan con regularidad. Precede cada secuencia una foto en plena página que se independiza del texto por la ausencia de leyenda. En doce secuencias se incluyen además dentro del relato otras fotos del mismo tamaño (en cuatro casos) o más pequeñas. Si bien en los libros de viajes españoles de los años sesenta las fotos ilustraban el relato y atestiguaban su veracidad, los vínculos que unen texto y relato se han vuelto ahora más complejos. Redundan en beneficio de un papel más importante de la foto en la figuración del espacio recorrido y de una recíproca intensificación semiológica. Gracias a su peculiaridad semiótica, la foto contribuye también a la reflexividad del género, a la autorrepresentación de la percep- 
ción y de la reeducación de la mirada. Paralelamente a la intertextualidad del relato, desarrolla una relación dialógica con otras series icónicas, fotográficas o pictóricas, que trasciende el «documento» y convierte la imagen en espacio de una experiencia artística.

\subsection{Imagen indicial y veridicidad}

Lo fotografiado existe, o más bien ha existido delante del objetivo -el «ça a été là» de R. Barthes ${ }^{23}$-, de lo cual se suele deducir abusivamente, particularmente en el periodismo, que ha existido tal como se representa y tal como lo cuenta el relato cuando, como lo recalca J. M. Schaeffer, la supuesta función testimonial de la imagen sólo se funda en una relación de compatibilidad entre imagen y texto ${ }^{24}$. En el relato de viaje, género que establece, al menos parcialmente, un pacto de lectura factual, también ha de legitimar la foto la veracidad el mensaje verbal, función que lo vincula a éste por una relación de subordinación. En España de sol a sol, el relato suele incluir un breve enunciado que permite identificar el referente de la imagen, cuando no lo hace el título de la secuencia. Acentúan la sensación de veracidad el aparente amateurismo, «errores» de encuadre (pp. 40, 82), subexposición (pp. 211, 228), contraluz (pp. 62, 248), foto borrosa (pp. 126, 138, 186, 228) cliché aparentemente no intencional (p. 34). Se intensifica la función de autentificación cuando las secuencias se acercan al reportaje por su temática como a propósito del racismo en los invernaderos de Almería o los dramas de la inmigración clandestina. Se multiplican entonces las fotos intercaladas en la secuencia, como en el género periodístico.

Cabe observar que la foto compite con otros mensajes visuales, el mapa general del recorrido, con sus etapas numeradas, colocado al principio del libro y los mapas parciales colocados debajo del título de las secuencias, El mapa general, que proporciona al lector una comprensión inmediata y sintética del trayecto, compensando las elisiones del relato, pone énfasis en el recorrido mientras que los mapas parciales producen un efecto de zoom sobre las sucesivas etapas. El mapa es un elemento recurrente de los libros de viajes cuya presencia contribuye, desde el umbral, a incluir el relato en este género ${ }^{25}$.

\subsection{Consonancia texto-imagen en la figuración del viaje}

En la recepción, la copresencia de texto e imagen implica un vaivén de uno a otro que genera capas sucesivas de semantización de ésta. A un

\footnotetext{
${ }^{23}$ BARTHES, Roland Barthes. La chambre claire. Paris: Seuil, 1980, pp. 120-121.

${ }^{24}$ SCHAEFFER, Jean-Marie. L'image précaire, op. cit., p. 140.

${ }^{25}$ Danièle MÉAUX califica el mapa de «lieu commun de la relation viatique». En: Voyages de photographes, op. cit., p. 44.
} 
primer momento de descubrimiento de la foto en sí misma, sucede una nueva etapa interpretativa generada por la contigüidad de la imagen y del texto y, más adelante, una tercera debida a la inclusión de la imagen en la serie icónica o icónico-verbal, en una organización reticular del conjunto en el que operan resonancias y contrastes ${ }^{26}$.

\section{Recepción de la foto descontextualizada}

La foto desprovista de leyenda aparece primero en su desnuda presencia descontextualizada. El lector-espectador descubre el objeto representado como «totalidad que se manifiesta visualmente» en una especie de «unión mística», según una metáfora de J. M. Schaeffer ${ }^{27}$. Ya subrayaba Roland Barthes la dificultad de distinguir la imagen de su referente; percibir el significante fotográfico — no arbitrario- exige un acto segundo de reflexión. La fascinación que produce la foto como fusión de la percepción y de lo percibido, es amplificada, por otra parte, por su naturaleza de «casi percepción» que favorece la identificación del espectador con la mirada del fotógrafo. En el libro de viaje semejante identificación participa de una estrategia de persuasión al facilitar la adhesión del espectador-lector al mundo representado.

\section{La foto, amplificador semántico}

La primera «lectura» va de la imagen al texto para invertirse durante o después de la lectura de la secuencia. Después de interpretar la imagen sobre la base de la propia experiencia del mundo - conocer es primero reconocer $^{28}$ - se vierte en ella un saber contextual debido a la contigüidad del texto y la imagen que la enriquece.

Resulta fácil identificar el referente de la foto «anti-poética» que precede la secuencia titulada «El bar, templo español» (p. 42), la cual recorta una porción de sala o pasillo en el que figuran arriba, a la izquierda, la cabeza naturalizada de un jabalí debajo la cual está colocada una máquina expendedora de cajetillas de cigarrillos, con su cable y el enchufe aparentes, mientras que, a la derecha, aparece la casi totalidad de la puerta que

\footnotetext{
${ }^{26}$ «Cada imagen —escribe Danièle MÉAUX a propósito de los libros de fotógrafoscobra sentido en relación con las demás, en función del lugar que ocupa en una organización interna». En: Voyages de photographes, op. cit., p. 20.

${ }^{27}$ Comentario acerca de una de las ocho funciones de la fotografía que distingue el filósofo, la «presentación autónoma». En: SCHAEFFER, Jean-Marie. L'image précaire, op. cit., p. 136. Recalca que la imagen en sí misma «no dice nada, no quiere decir nada, muestra» (p. 210); de ahí que la considere precaria.

${ }^{28}$ SCHAEFFER, Jean-Marie. L'image précaire, op. cit, pp. 92-93.
} 
lleva al baño de caballeros. El impacto del lenguaje icónico convierte lo que no se suele ver o se desprecia en una «epifanía [...] amplificadora de existencia ${ }^{29}$, versión icónica del endotismo. En contacto con el relato que asimila el bar a un templo de lo castizo, la foto se vuelve antítesis de los estereotipos homogeneizadores del turismo de masa, puesta al servicio de la poética de lo infraordinario. La foto celebra lo que se suele ver de paso y con el rabillo del ojo.

Otra celebración de lo cotidiano propone la que acompaña la secuencia 11 (p. 70): un paisaje marítimo banal de acantilados sirve de telón de fondo a un primer plano que capta un instante fugaz, esencia de la «instantánea». Un hombre duerme, sentado en un banco, prominente la tripa, rodeado por una bicicleta de niño detrás de la cual se yergue sobre un telón de fondo marítimo una insólita escoba mientras que ocupa el centro de la banda inferior de la imagen una gallina que parece correr, con las alas abiertas, en equilibrio sobre una sola pata. Lo insólito dignifica en ella lo banal. A la luz de la secuencia que sigue, se añaden significaciones nuevas: la «virginidad» de un lugar no frecuentado por los turistas (el personaje que duerme y la gallina dan la espalda al mar, parte integrante de la vida de los lugareños) y la figuración del «tempo» lento de una vida acompasada por las exigencias del cuerpo (sueño), de la edad (niño y adulto) y del trabajo (escoba). La foto aboga aún por el rechazo del turismo-huida, como lo confirma, en la secuencia, la figura modélica del escultor Leiro cuya vida no queda escindida esquizofrénicamente entre trabajo y asueto. Del mismo modo, el contexto verbal confiere una significación polémica a las fotos borrosas o misteriosas, en blanco y negro, que se convierten en negativo de la postal llamativa. El relato enriquece pues retrospectivamente la interpretación de la imagen.

Al revés, más que de redundancia, aunque ésta tenga una función persuasiva, cabe hablar de una intensificación del sentido del texto por la imagen. Queda patente, por ejemplo, en el impacto de los hermosos retratos de hombres o mujeres, momentánea o definitivamente anónimos, que incluye el libro (pp. 26, 30, 1150, 162, 183, 196, 204), los cuales gozan de fuerte presencia por su tamaño, por pertenecer a un género fotográfico y pictórico consagrado y por su calidad estética. Retrospectivamente, la lectura da a entender que esas figuras — de trabajadores o intelectuales las más veces - amplifican la valoración del hombre o de la mujer cabal, que no ha sido aniquilado/a por la noria urbana que plasma la penúltima secuencia dedicada a la ciudad dormitorio de Getafe. Se entiende entonces por qué la fotógrafa orienta la mirada del espectador hacia las manos del torero (p. 196 y 199): éstas simbolizan al hombre que se hace a sí mismo por su arte, sacando todo lo que lleva dentro como lo explica el enuncia-

\footnotetext{
${ }^{29}$ MÉAUX, Danièle. Voyages de photographes, op. cit, p. 97.
} 
do verbal (p.199). Los retratos resultan ser la versión icónica del humanismo que promueve el relato.

\section{Estereotipo y arte de persuadir}

Texto e imagen echan mano de una reserva de estereotipos que proceden de un imaginario colectivo y participa de la función argumentativa de la imagen tanto como del relato. Si el estereotipo puede limitar el alcance hermenéutico de la foto por difundir la doxa, al revés contribuye también a remozar la mirada por su transformación artística y a favorecer la adhesión del lector-espectador al mensaje como se observa en la reelaboración del estereotipo del camino, topos de la literatura de viajes. Ambas caras de la función argumentativa, de comunión ${ }^{30}$ y demarcación, se imbrican en las fotos de Corina Arranz, en consonancia con la dualidad del discurso polémico del narrador. Es en este punto de particular interés la foto de la estela de una motora (p. 216) que invita primero a la adhesión y luego al distanciamiento. Ocupa las tres cuartas partes de la imagen y fue sacada casi a ras del agua, en una visión de frente, perspectiva que le da al espectador la sensación de viajar en otra motora similar y quedar directamente implicado. La estela que dibuja la motora connota, en el contexto de libro, los placeres veraniegos, la libertad de un camino que abre el mismo viajero. En un plano existencial, es por supuesto una variante del estereotipo del camino de la vida. La confrontación de la imagen y de la secuencia inaugurada por ella aumenta la polisemia al vincularla con «El nuevo muro de Berlín» — título de la secuencia- edificado para contener la inmigración africana ilegal en Ceuta. Se invierte entonces el estereotipo que pasa a simbolizar la imposibilidad del viaje o su final trágico en las aguas del Estrecho. La misma imagen figura el sueño de los candidatos a la inmigración y su fracaso. La violencia de la inversión simbólica proviene precisamente de la superposición de dos interpretaciones opuestas en un mismo significante que adquiere, por eso mismo, una densidad semántica y una fuerza emotiva superlativas. La inversión simbólica conmueve al destinatario del mensaje que adhiere espontáneamente a la primera interpretación eufórica antes de rechazar horrorizado la que le revela el relato. Ese doble movimiento de adhesión y rechazo facilita la aceptación del mensaje ético.

\footnotetext{
${ }^{30}$ Véase AMOSSY, Ruth y ROSEN, Elisheva. Les discours du cliché. Paris: Éditions SEDES/CDU, 1982. Lo dicho acerca del discurso verbal se aplica a la imagen: «[la figure lexicalisée] prise en charge par le récepteur qui retrouve dans les métaphores de cet autre 'je' les siennes propres, et s'y projette à son tour dans un mouvement spéculaire qui fonde le jeu de doubles. L'identification affective s'effectue sur le terrain commun des expressions toutes faites» (p. 141).
} 
El efecto pragmático del estereotipo (influir en el juicio y el comportamiento del espectador) lo convierte en una potente figura de comunión que participa de la articulación de los dos planos de significación, societal y existencial, que caracteriza el libro y lo distingue de sus predecesores del siglo XX. Merecería un estudio pormenorizado, que no permite el espacio de este artículo, el motivo del árbol declinado en tres fotos interpretables como un conjunto narrativo en el que se contempla, sucesivamente, unos olivos majestuosos, catedral vegetal y cueva protectora para el hombre (p. 78), la copa de un árbol zarandeado por el viento, símbolo de la precariedad humana y tal vez de la misma naturaleza (p. 82) y, casi al final del libro, el esqueleto de un imponente alcornoque seco (p. 256) emblemático de la condición humana y susceptible de representar también los estragos ecológicos. La misma serie puede aunar por consiguiente un simbolismo individual y otro colectivo que vincula ontogénesis (la trayectoria humana de la cuna a la sepultura) y filogénesis (la historia del planeta a través de la vida y muerte de los árboles). La evidencia del primero facilita la aceptación del segundo.

\subsection{Entre reflexividad y experiencia estética}

Si bien la foto genera un potente efecto de realidad, comparte con el relato literario la capacidad de confundir en un mismo significante representación y metarrepresentación. Centrándose en su peculiaridad semiótica, se independiza del relato aunque converjan sus poéticas del viaje.

\section{De la fotografía a la fotógrafa}

Aunque la fotógrafa no aparezca como objeto explicito de la representación, la presencia del sujeto de la percepción, interioridad abierta al mundo exterior, se deduce de los rasgos formales de la imagen que revelan su posición ante los objetos. La sugieren los encuadres que delimitan el campo visual: el retrovisor-objetivo (p. 154), la ventanilla (p. 276), el arco de una iglesia (p. 55). La perspectiva frontal (pp. 78, 216) o lateral (p. 188), la superposición de los planos marcadores de cercanía o lejanía (pp. 146, 162, 236), la borrosidad de un primerísimo plano (p. 228), figuran en negativo la mirada y la variación de la representación en función de la posición adoptada. La mirada se tematiza cuando se representa la de los personajes (hombres o niños contemplando el mar, pp. 63 y 146; mujeres a la ventana, pp. 89, 99, 240; individuo mirando por un telescopio, p. 228). Enfatizan la actividad del fotógrafo los rasgos formales que hacen percibir la elaboración de la representación: los marcos que distribuyen el espacio en campo y fuera de campo $^{31}$ y los recursos de una «estética del

\footnotetext{
${ }^{31}$ Ibidem, pp. 119-120.
} 
error» ${ }^{32}$ : encuadre defectuoso (pp. 40, 82, 112), foto borrosa, como de amateur (pp. 34, 126, 186, 211), granulación aparente (p. 228). Una foto de la serie parece sacada por inadvertencia (p. 34) por lo borroso de las formas, la falta de encuadre, lo confuso de los objetos anegados en la sombra; su unidad proviene exclusivamente de referentes relativos al espectáculo: un escenario al aire libre o la pantalla de un cine con dos manchas luminosas como huellas de una imagen, unas sombras como de sillas, una silueta lejana y de espaldas como de espectador, una cabeza de perfil que surge en primer plano sin que se sepa muy bien si pasa delante del objetivo o forma parte de la imagen en el escenario-pantalla. Esta foto es una «mise en abyme» de la representación, sus espacios, sus soportes, su elaboración así como de la naturaleza de «instantánea» de la foto, encuentro fugaz e irrepetible de un objeto y de una mirada.

\section{Función poética de la imagen}

«Sugerir es crear, describir es destruir» afirmaba Robert Doisneau ${ }^{33}$ que privilegiaba los valores connotativos de la foto, la solicitación de la afectividad y del imaginario del receptor y anteponía la función poética a la función informativa, postura que comparte Corina Arranz. La sugestión puede proceder de la proporción como en el sendero de los olivos donde la masa vegetal, que ocupa las dos terceras partes de la imagen connota la fragilidad del hombre y una naturaleza protectora (p. 78). Puede generarla un efecto de contigüidad como en la foto del niño de la veleta (p. 236) en brazos de su madre y mirando hacia el objetivo, que connota, por un efecto de contigüidad, la voluntad del narrador de «poner ojos de niño» (pp. 238-239) que se expresa en la misma secuencia. El gallo de la veleta que ocupa el primer plano, indicando el norte con la letra $\mathrm{N}$ bien visible, desvela por su parte metafóricamente la intencionalidad de un libro que pretende orientar al lector en el desciframiento de la realidad actual, como lo hacen, por otra parte, dos fotos de faros (pp. 65 y 248). Lo cual viene confirmado por unos versos de Celan — «En los dos polos / de la rosa de fractura, legible: / tu palabra proscrita. / Norteverdea. Surclara» (pp. 206-207) — que sugieren una concepción neorromántica del poeta-viajero-fotógrafo.

Una de las fotografías más sugestivas del libro es la que acompaña la secuencia titulada «La casa de la golondrina» (p. 260). Golpea al espectador su aspecto surrealista: en una pared encalada, a ras del techo, sale de una masa oscura rodeada de manchitas del mismo color —el título de la

\footnotetext{
${ }^{32}$ Véase MÉAUX, Danièle. Voyages de photographes, op. cit., p. 142.

33 Afirmación citada por el fotógrafo Michail Meyer entrevistado por Philippe Pache. «Photographie d'art, photographie de presse: des vases communicants». En: Photos de presse. Haver, Gianni (dir.). Lausanne: Éditions Antipodes, p. 241.
} 
secuencia que hace de leyenda revela que es un nido de golondrinas- un cable desnudo del que cuelga una bombilla desnuda ensuciada por las deyecciones de las aves. La foto suscita primero la experiencia estética de lo insólito capaz de despertar lo familiar: el cable eléctrico parece provenir directamente del nido. El examen desentraña la polisemia de la imagen, su alcance referencial (interior de un edificio en el campo) suplantado por las significaciones connotativas. El cable insólito sugiere una continuidad entre lo animal y lo humano, entre dos formas de creación (del nido / de una técnica de alumbramiento). El movimiento de los ojos de arriba hacia abajo, en el sentido del flujo eléctrico, sugiere por su parte el paso de la oscuridad a la luz que puede interpretarse en la filogénesis como el recorrido de la humanidad (En Central eléctrica (1958), Jesús López Pacheco hacía enfrentarse precisamente las tinieblas del atraso rural y la luz, regalo de la técnica y del progreso). En una reflexión metatextual, figura la voluntad de disipar la opacidad del mundo manifiesta en la crítica del discurso periodístico. En un plano existencial y ético, puede interpretarse incluso, a partir del mismo simbolismo de la sombra y de la luz, como un himno a la vida contrapuesto a los aspectos deletéreos del mundo actual. La imagen condensa pues, con una gran economía de medios, una multiplicidad de sentidos connotativos, susceptibles de actualizarse en el acto de recepción, en los diferentes planos que combina el libro.

\section{Intericonicidad}

La autonomía de la serie icónica y su poeticidad se intensifican en el diálogo que la foto establece con otras representaciones icónicas de corte artístico, fotográficas o pictóricas. La existencia de la relación intericónica depende de su reconocimiento por un espectador que comparta, al menos parcialmente, la cultura del creador. Siendo una figura más de comunión, establece entre ellos una complicidad que facilita la adhesión de aquél al mensaje. Traslada, por otra parte, el referente fotográfico del ámbito referencial a un contexto artístico que pone de realce una intencionalidad estética. Los cambios que introduce la foto en relación con el/los hipoiconos ${ }^{34}$ son significativos de una postura personal original respecto al contexto referencial, al viaje o a la propia estética.

Cuatro imágenes llaman la atención por vincular foto y pintura, por articular las vertientes referencial, existencial y metarrepresentativa de la foto sin dejar de participar de una estética de lo banal. Dos de ellas reto-

\footnotetext{
${ }^{34}$ Véase el paralelismo que establece Liliane Louvel entre transtextualidad y transpicturalidad en: LOUVEL, Liliane. L'eil du texte. Texte et image dans la littérature de langue anglaise. Toulouse: Presses Universitaires du Mirail, 1988 (cap. 5, «Iconotextualité et transpicturalité, essai de typologie»).
} 
man el motivo literario y pictórico de la ventana. Una mujer, de espaldas, apoyándose con las manos en el alféizar de una ventana alta con barrotes, contempla un paisaje desdibujado (p. 240); una mujer, casi de espaldas, sentada en el sillón o la cama de una habitación impersonal en la que destacan las masas blancas de la ropa de cama, mira también por una ventana apenas visible a la izquierda. La primera recuerda claramente el cuadro de Dalí «Muchacha en la ventana» (1925); del espacio cerrado y del hieratismo de la mujer se desprende, en la segunda, una melancolía característica de los interiores de Hopper, en «Habitación de hotel» por ejemplo (1931). Según el relato, los referentes son respectivamente una cárcel de mujeres y un hospital. Los cambios introducidos — supresión de los colores, sustitución del mar por los barrotes y ausencia de paisaje- o, en el segundo caso, sustitución de la lectura que compensa en los cuadros de Hopper la soledad del personaje por la contemplación de un paisaje vislumbrado que parece ser un cementerio, proponen dos versiones iconográficas de un viaje imposible o hacia la nada. La temática del viaje se confirma en las otras dos fotos. En la secuencia dedicada a Getafe se inserta un gigantesco mural que representa un paisaje urbano y rural algo borroso e incluye a la derecha, en el ángulo inferior, un hombre que enseña el plano de una ciudad, como en el cuadro de El Greco «Vista y plano de Toledo» (p. 272). La cuarta foto representa un par de zapatillas con cordones de bramante abandonadas en la hierba (p. 232). El lector asocia el motivo al cuadro «Les souliers aux lacets» de Van Gogh (1886), unos borceguíes desgastados, así como, en el área fotográfica, a «Abandonned schoes» del americano Edward Weston (1937), otro par de borceguíes tirados en el suelo contra lo que parece ser una roca. Además de las connotaciones disfóricas de ambas fotos (el mural de Getafe es paródico por aplicarse a lo que se describe a continuación como negación de la ciudad y el relato atribuye las alpargatas a un inmigrante clandestino), las dos imágenes remiten al viaje. Los zapatos, tópico de la indumentaria del viajero, ya no simbolizan la unidad indestructible del campesino y de la tierra, como en el comentario de Heidegger al cuadro de Van Gogh ${ }^{35}$, sino la precariedad del hombre que ha perdido sus raíces en el mundo global. Crea, además, por la unidad del objeto referible a dos clases de individuos, una relación de empatía entre esos seres andariegos que son el viajero y los marginados que marca una postura ética de solidaridad. Por su parte, al incluir el plano -y el mismo arquitecto que lo presenta- en el paisaje, la parodia del cuadro del Greco se vuelve metarrepresentación del viaje y de su relato y, pintado en la fachada trasera de un edificio, manifiesta el proyecto de

${ }^{35}$ Véase la conferencia de Heidegger de 1936 acerca de este cuadro de Van Gogh, en su versión francesa: «L'origine de l'œuvre d'art». En: BROKMEIR, Wolfgang (trad.). Chemins qui ne mènent nulle part. París: Gallimard, 1962. 
desvelar la cara oscura de la realidad cotidiana. Las dos fotos revitalizan lo banal mediante lo insólito: hace falta una adaptación de la mirada para identificar el mural y sólo el relato permite entender que las manchitas blancas que salpican las alpargatas y la hierba resultan ser caracoles. Se cumple el proyecto endótico.

\section{CONCLUSIÓN}

Varias son las características que diferencian España de sol a sol de los libros de viajes que, cuatro décadas atrás, los escritores del «realismo social» dedicaban a sus recorridos por España. Si bien todos conciben el género como una respuesta ética al contexto, éste era nacional y sociopolítico para los que combatían un régimen dictatorial y su propaganda mientras que el libro de A. Armada, siendo una respuesta a problemas societales comunes a las sociedades posindustriales en un mundo globalizado, rebasa de hecho el espacio de viaje físico y las fronteras de la Península Ibérica. Como sus predecesores del siglo XX, España de sol a sol es un libro polémico pero, en vez de limitar casi exclusivamente la intertextualidad a la propaganda política y de cultivarla veladamente por motivos de censura, la diversifica y la ostenta. Añade en efecto a los discursos sociales la presencia masiva de referencias literarias y culturales que cimientan el humanismo del relato y lo enraízan en el ámbito de la literatura. Frente a un uso del lenguaje predominantemente monosémico de los relatos del «realismo social» que pretendían «reflejar» lo más fielmente posible una realidad nacional manipulada por la propaganda, el relato de A. Armada es polisémico y superpone tres planos de interpretación - referencial, existencial y societal - generando una condensación e intensificación semánticas del mensaje. De ahí que la función documental, esencial en los años sesenta, se minore en beneficio de un discurso abiertamente interpretativo que acercaría el relato de viaje al ensayo si la modalidad argumentativa escogida no privilegiara los recursos poéticos de la metáfora y el símbolo en los que se articulan lo particular y lo general. Otra aportación del libro es la evolución del papel de la fotografía que en él se observa. Casi exclusivamente ilustrativa en los relatos de viaje del «realismo social», ocupa en España de sol a sol un espacio más importante y teje vínculos complejos con el relato, de complementariedad más que de redundancia. $\mathrm{Si}$ bien los enunciados verbales aclaran su referencialidad y cumplen su función de autentificación, añade al texto una intensificación semántica y genera en el espectador-lector reacciones afectivas, las cuales participan de un dispositivo argumentativo al facilitar la aceptación del mensaje. En fin, la imagen, como el relato, participan ostensiblemente de una reflexión sobre la representación y sobre el mismo género que sólo podía tener una pre- 
sencia lateral cuarenta años atrás. La fotografía conquista ahora su autonomía para volverse, además de otras funciones, experiencia estética, lo que contribuye a afirmar la pertenencia de este libro de viaje al área de la literatura.

\section{REFERENCIAS BIBLIOGRÁFICAS}

ALBURQUERQUE GARCÍA, Luis. «Periodismo y literatura: el 'Relato de viajes' como género híbrido a la luz de la pragmática». En: HERNÁNDEZ DE GUERRERO, José Antonio; María del Carmen GARCÍA TEJERA; Isabel MORALES SÁNCHEZ y Fátima COCA RAMÍREZ (eds.). Retórica, Literatura y Periodismo. Actas del V Seminario Emilio Castelar. 2004. Cádiz: Publicaciones de la Universidad de Cádiz, 2006, noviembre-diciembre, pp.187-176.

ALMARCEGUI, Patricia. «Cómo escribir hoy un libro de viaje». Quimera, n. ${ }^{\circ} 311$, oct. 2009, p. 38.

AMOSSY, Ruth y ROSEN, Elisheva. Les discours du cliché. Paris: Éditions SEDES/CDU, 1982.

ARMADA, Alfonso. España de sol a sol. Cuaderno de estío. Viaje de cincuenta y un días por la Península Ibérica en verano 2000. Barcelona: Ediciones Península, 2001.

AUGÉ, Marc. L'Impossible Voyage. Paris: Éditions Rivages Poche, coll. Petite Bibliothèque, 1997.

BARTHES, Roland Barthes. La chambre claire. Paris: Seuil, 1980.

CHAMPEAU, Geneviève. Enjeux du réalisme dans le roman sous le franquisme. Madrid: Casa de Velázquez, 1995.

HAVER, Gianni (dir.). Photos de presse. Lausanne: Éditions Antipodes, p. 241.

HEIDEGGER, Martin. «L'origine de l'œuvre d'art». (1336). En: Chemins qui ne mènent nulle part (trad. de Wolfgang Brokmeir). Paris: Gallimard, 1962.

LIPOVETSKY, Gilles. L'ère du vide. Paris: Gallimard, 1983.

LOUVEL, Liliane. L'œil du texte. Texte et image dans la littérature de langue anglaise. Toulouse: Presses Universitaires du Mirail, 1988.

LYOTARD, Jean-François. La condition postmoderne. Paris: Éditions de Minuit, 1979.

MÉAUX, Danièle. Voyages de photographes. Saint-Étienne: Publication de l'Université de Saint-Étienne, 2009.

PÉREC, Georges. L'infra-ordinaire. Paris: Seuil, 1969.

POUSSIN, Alexandre y TESSON, Sylvain. On a roulé sur la terre. Paris: Pocket, 2008.

POUSSIN Alexandre y POUSSIN Sonia. Africa Trek, 14000 kilomètres dans les pas de l'Homme. Paris: Pocket, 2007. Tomo 1, 2004 y tomo 2, 2007.

RUBIN SULEIMAN, Susan. Le roman à thèse ou l'autorité fictive. Paris: PUF, coll. Écritures, 1983.

SCHAEFFER, Jean-Marie. L'image précaire. Du dispositif photographique. Paris: Seuil, coll. Poétique.

VATTIMO, Gianni et al. En torno a la postmodernidad. Barcelona: Anthropos, 1990.

Fecha de recepción: 6 de abril de 2010

Fecha de aceptación: 16 de diciembre de 2010 